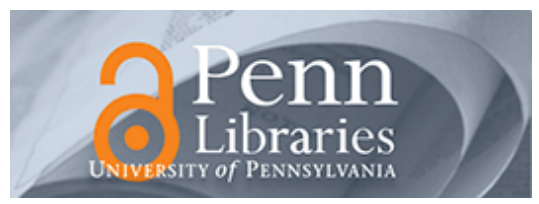

University of Pennsylvania ScholarlyCommons

March 2005

\title{
The Gender Gap among Teen Survey Respondents: Why are Boys more Likely to Report a Gun in the Home than Girls?
}

Philip J. Cook

Duke University

Susan B. Sorenson

University of Pennsylvania, sorenson@sp2.upenn.edu

Follow this and additional works at: https://repository.upenn.edu/spp_papers

\section{Recommended Citation}

Cook, P. J., \& Sorenson, S. B. (2005). The Gender Gap among Teen Survey Respondents: Why are Boys more Likely to Report a Gun in the Home than Girls?. Retrieved from https://repository.upenn.edu/

spp_papers/71

Postprint version. Published in Journal of Quantitative Criminology, Volume 22, Issue 1, March 2005, pages 61-76. Publisher URL: http://dx.doi.org/10.1007/s10940-005-9002-7.

NOTE: At the time of publication, author Susan B. Sorenson was affiliated with the University of California. Currently (August 2007), she is a faculty member in the School of Social Policy and Practice at the University of Pennsylvania.

This paper is posted at ScholarlyCommons. https://repository.upenn.edu/spp_papers/71

For more information, please contact repository@pobox.upenn.edu. 


\title{
The Gender Gap among Teen Survey Respondents: Why are Boys more Likely to Report a Gun in the Home than Girls?
}

\author{
Abstract \\ It is a reliable though unexplained feature of national surveys that include items on gun ownership that \\ wives are less likely to report a gun in the home than husbands. In this article we extend the inquiry \\ regarding this gender gap in reporting of household guns to include adolescent children (age 12-17 \\ years). The California Health Interview Survey of 2001, the largest-ever state survey of its kind, includes \\ over $\mathbf{4 0 0 0}$ marital households in which both a parent and adolescent child were interviewed and asked \\ whether there was a gun in the home. There is little "age gap" in reporting - California teens are almost as \\ likely to say that there is a gun as are their parents - but there is a gender gap among both the teens and \\ their parents. We also find a large gap in personal experience with guns - boys are three times as likely to \\ report hunting or shooting with a family member than girls. This difference in experience fully accounts \\ for the gender gap in reporting. The relevance of these findings for the interpretation of survey data is \\ clear. Whether there is a gun reported in a home depends to a remarkable extent on which member of the \\ household is asked the question. Hence, the method of selection of respondent(s) from within a \\ household will affect estimates of the patterns and prevalence of gun ownership, and, potentially, the \\ accuracy of case-control studies that use self-report information about guns in the home.
}

\section{Keywords}

firearms, gun ownership, gun experience, sex differences, survey methods, case-control methodology

\section{Comments}

Postprint version. Published in Journal of Quantitative Criminology, Volume 22, Issue 1, March 2005, pages 61-76. Publisher URL: http://dx.doi.org/10.1007/s10940-005-9002-7.

NOTE: At the time of publication, author Susan B. Sorenson was affiliated with the University of California. Currently (August 2007), she is a faculty member in the School of Social Policy and Practice at the University of Pennsylvania. 
March 3, 2005

The gender gap among teen survey respondents:

Why are boys more likely to report a gun in the home than girls?

\author{
Philip J. Cook ${ }^{1}$ \\ Susan B. Sorenson ${ }^{2}$ \\ ${ }^{1}$ Sanford Institute of Public Policy, Duke University, Durham, North Carolina \\ ${ }^{2}$ School of Public Health, University of California, Los Angeles
}

Running head: “The Gender Gap in Teen Reporting of Guns”

This is a working version of the paper which was published in the Journal of Quantitative Criminology, 2006; 22, 61-76.

For the published paper, please access the Journal's webpage. 
The gender gap among teen survey respondents:

Why are boys more likely to report a gun in the home than girls?

\begin{abstract}
It is a reliable feature of national surveys that include items on gun ownership that wives are less likely to report a gun in the home than husbands. In this article we extend the inquiry regarding this gender gap in reporting of household guns to include adolescent children (age 12-17 years). The California Health Interview Survey of 2001, the largest-ever state survey of its kind, includes over 4,000 marital households in which both a parent and adolescent child were interviewed and asked whether there was a gun in the home. There is little "age gap” in reporting - California teens are almost as likely to say that there is a gun as are their parents but there is a gender gap among both the teens and their parents. We also find a large gap in personal experience with guns - boys are three times as likely to report hunting or shooting with a family member than girls. This difference in experience mediates the gender gap in reporting, as does living in a rural area and ethnicity.

The relevance of these findings for survey design is clear. The gender of the respondent has a substantial effect on the likelihood of reporting a gun kept in the home. That differential reporting bias will affect estimates of the patterns and prevalence of gun ownership, and, potentially, the accuracy of case-control studies that use self-report information about guns in the home.
\end{abstract}

Key words: Firearms, Gun ownership, gun experience, sex differences, survey methods, casecontrol methodology 
The gender gap among teen survey respondents:

Why are boys more likely to report a gun in the home than girls?

\section{Introduction}

When it comes to guns, the gulf between the sexes could scarcely be wider (Zimring 2003). While $40 \%$ of men personally own a gun in the United States, only $10 \%$ of women do so (Cook and Ludwig 1996). Males predominate in the armed forces and as participants in hunting and other gun sports. Men as a group are far less likely than women to support gun-control measures and more likely to endorse the view that keeping a gun is important for self-defense (Teret et al. 1998).

Despite these well-known differences in gun-involvement and attitudes, it may come as a surprise that there is even a gender gap in the likelihood that a gun possession will be reported to a survey interviewer. While it seems reasonable to suppose that a wife knows whether there is a gun in her home (even if it does not belong to her personally), previous research has demonstrated that a gender gap on gun-in-the-home survey items is a reliable feature of national surveys (Ludwig, Cook, and Smith 1998; Cook and Ludwig 1996; Kleck 1997). For example, the results from one such survey suggest that the estimated number of guns possessed by marital households could either be 114 million (based on the husbands' responses) or 60 million (based on the wives’ responses). ${ }^{1}$

\footnotetext{
${ }^{1}$ The 1994 National Survey of the Private Ownership of Firearms, conducted by Chilton Research Services for the Police Foundation under the sponsorship of the National Institute of Justice. Details about the survey are in Cook and Ludwig (1996). See Ludwig, Cook and Smith (1998) for this computation.
} 
There are few household surveys of adolescents that ask about guns in the home. ${ }^{2} \mathrm{~A}$ recent household survey, however, finds that there also is a gender gap in reports of household guns in surveys of adolescents. Even when taking other demographic characteristics into account, adolescent boys are more likely than adolescent girls to report that there is a gun in the home (Sorenson and Vittes, 2004).

In this article we extend the inquiry on sex differences in knowledge of household guns to include adolescents (ages 12-17 years) and attempt to understand why the difference exists. The California Health Interview Survey of 2001 (CHIS), the largest-ever state survey of its kind, includes over 4,000 marital households in which both a parent and adolescent child were interviewed and asked whether there was a gun in the home. There is little “age gap” in reporting - the teens are almost as likely to say that there is a gun as the parents - but there is a gender gap among the teens. We also find a large gap in personal experience with guns - boys are three times as likely to report hunting or shooting with a family member than girls. This difference in experience mediates the gender gap in reporting, as does living in a rural area and ethnicity.

The relevance of these findings for survey design is clear. Surveys of adolescent boys will find a higher prevalence of household guns than surveys of adolescent girls. The response pattern is also of interest in designing case-control studies about the risks of keeping a gun at home, which have utilized interviews with household members to establish whether guns are present in the homes of "cases" and "controls."

\footnotetext{
${ }^{2}$ Most research on adolescents and guns focuses on gun carrying or gun ownership among adolescent boys (e.g., Lizotte, Tesoriero, Thornberry, and Krohn, 1994; Sheley and Wright, 1993) largely because few girls report owning guns.
} 
Here is a brief roadmap for what follows. We begin by describing CHIS. The analysis of these data begins with documentation of the gender gap for adults and proceeds to analyze the relevant patterns for adolescent respondents. We conclude with a summary and brief discussion of the implications.

\section{The California Health Interview Survey}

The data used for this study come from the California Health Interview Survey of 2001 (CHIS). Interviews with adults in over 55,000 households were conducted between November 2000 and October 2001. Interviews were also completed with 5,801 adolescent (age 12-17) members of these households. CHIS is the largest state health survey ever undertaken in the United States.

The survey covered a variety of health-related topics, including access to medical care and medical-insurance coverage. A few items on gun ownership, experience with guns, and gunshot injuries were also included, together with demographic and socioeconomic information.

The Survey is a random-digit-dialing (RDD) telephone survey of California households designed to produce accurate estimates for the whole state and for various geographic and demographic subgroups. Individuals living in group quarters of ten or more unrelated people were excluded from the sampling frame, as were households that lacked a telephone (about 5\%

of the total). Telephone numbers were selected through a stratified- random-sampling procedure. When an interviewer made contact with a householder, there was an attempt to complete a brief screening questionnaire, which included a listing of household members. An adult was then selected at random from the list, and interviewed about personal and household matters.

In those households where the adult respondent was parent or guardian of an adolescent living in the home, permission was sought from the respondent to interview that adolescent. (If 
there was more than one, the adolescent was selected at random from the list of adolescents in the household.) The survey instrument for adolescents focused on health issues and medical care, including items on gun ownership and experience.

The survey was successful in completing screening interviews with 59\% of eligible households that were selected into the sample. Interviews were completed with the selected adult respondent in $64 \%$ of the cases in which a screening interview was completed; the overall response rate for adults, then, was 38\%. For those households where the adult respondent completed the questionnaire and which included an eligible adolescent, the completion rate for the adolescent questionnaire was $63.5 \%$ (The response rate was $84.5 \%$ in cases where the parent gave permission.) The overall response rate for adolescents was, then, approximately 24\%. The double layer of permission required in surveys of children and adolescents typically reduces the response rate substantially. Despite the low response rate, the quality of the sample was fairly high.

In order to allow for the computation of population estimates, a set of weights are included in the public-use-data file. These weights support state-level estimates for the number of individuals represented by each response. The weights differ among records for a number of reasons: some groups were intentionally over-sampled relative to others, the sampling frame did not provide full coverage of some groups, some households have more than one telephone number, the number of adults per household differs, and non-response rates differ among groups.

Our interest is in making estimates relevant to households rather than individuals, and unfortunately CHIS does not include household weights. But for the subset of respondents we analyze, all of whom are in marital households, individual weights would be nearly proportional to household weights. That would be true if every marital household had just two adults in it. 
As it turns out, most (72\%) of these households do have two adults, while $21 \%$ have three and $6 \%$ have four or more. ${ }^{3}$

\section{The Marital Gender Gap in Survey Responses}

Standard practice in surveys intended to measure household characteristics is to interview just one respondent. That approach is economical, but provides no basis for assessing differences among household members with respect to their knowledge of the household or their willingness to share that knowledge with an interviewer. In the case of guns in the home, those differences are large and systematic.

In particular, earlier research (Ludwig, Cook, and Smith 1998; Kleck 1997; Cook and Ludwig 1996) documented a gender gap between husbands and wives in reporting household gun ownership in surveys. For example, in 11 of the 12 waves of the General Social Survey between 1980 and 1996, marital households were more likely to report a gun in the home if the husband was selected as the respondent than the wife, with a median gap of 7 percentage points. (The choice of whether to interview the husband or wife in the GSS is made at random, so there should be no systematic difference in reporting between the sexes.) A cross-sectional national telephone survey on gun ownership (the 1994 National Study of the Private Ownership of Firearms) found that the estimated number of guns possessed by marital households would either be 114 million (based on the husbands' responses) or 60 million (based on the wives' responses). An explanation for this gap begins with the facts that guns (unlike, say, toasters) tend to belong to individuals rather than households, and that husbands are four or five times as likely to say they personally own a gun as wives; we can speculate that wives often do not know about the

\footnotetext{
${ }^{3}$ Readers interested in response rate calculations and other methodological information
} 
gun in the home, or tend to be less comfortable than their husbands about mentioning it to an interviewer. $^{4}$

Here we document the gender gap in responses by marital households in the CHIS. As in previous research, the focus on marital households is dictated by a methodological consideration. Logically, the correct answer regarding a household item is the same for a husband and wife living together. In a survey in which the choice between husband and wife is made at random, the true prevalence of guns for the subsample in which wives are the respondents should be approximately the same as for the subsample in which husbands are the respondents. A difference in these prevalence estimates that exceeds what would be expected from sampling error is evidence of differential response error.

In CHIS, a total of 27,810 people were interviewed who said that they were married and that their spouses lived with them. Table I displays the distribution of gun prevalence estimates based on the question "Are any firearms now kept in or around your home?”5 Overall, 24.8\% of the adults in marital households reported a gun in the home and 3.5\% reported that they did not know. As expected, husbands were much more likely (25\% more likely, a difference of 7.5 percentage points) to report a gun in the home than wives. The difference in those who denied that there was a gun in the home is 9 percentage points (67.3\% of husbands, $76.3 \%$ of wives). (It should be noted that any difference exceeding 2.5 percentage points is significantly different from zero at the $5 \%$ level.)

can consult a series of online methodological reports (CHIS, 2002).

${ }^{4}$ We cannot rule out the possibility that some respondents claim there is a gun in the home when there is not, and that sort of "false positive" is more likely to be made by males than females. ${ }^{5}$ Following this question, the respondent was told "Include those kept in a garage, outdoor storage area, car, truck, or other motor vehicles. When I say firearms or guns I mean rifles, shotguns, pistols, revolvers, or other firearms. Do NOT include BB guns, air guns, or toy guns.” 
CHIS did not ask adults about the number of guns in the home, but did have two followup items on handguns: "Are any of the firearms in or around your home handguns, such as pistols or revolvers?” and "How many of these guns are handguns?” Overall, $14.9 \%$ of married adults said that there were one or more handguns in the home. Thus, about $60 \%$ of the gunowning households include one or more handguns in their collection. The gender gap for this item emerges both with respect to whether there is a handgun, and with respect to how many. Overall, $10.5 \%$ of the wives reported having a handgun in the home (50\% of those who reported that there was a gun), compared with $18.2 \%$ of husbands ( $64 \%$ of those who reported a gun). Husbands were almost three times as likely to report a number of handguns in excess of two, and the overall stock of handguns in marital households in California would be estimated to be over twice as large based on the husbands' responses as the wives'.

In sum, the gender gap for married respondents in CHIS is similar to that found in national surveys, which is to say, remarkably large. The following observations may be helpful in understanding this gap. Gun-owning households differ widely with respect to the "publicness” of the gun or guns kept there. At one extreme are homes where a gun rack is on display or in which members of the family regularly participate in sporting uses of the guns, so that the existence of the guns is no secret to any member or friend of the family. At the other extreme are households in which the gun - perhaps taken as a war souvenir or inherited -- is kept out of sight in the attic, forgotten or unknown to all except the owner. A possibly related dimension of "public-ness" has to do with the willingness to mention the gun to a stranger - in particular, a telephone interviewer. We develop these ideas further after analyzing the answers of teenage children concerning the presence of a gun in the home. 


\section{The Gender Gap Among Teens}

Adult respondents who had a teenage (12-17 year old) child living at home were asked for permission to interview him or her. (If they had more than one teen at home, the designated respondent was selected at random.) Of the 5,801 teens who were interviewed, 4,099 were living in a marital household. In what follows we focus on this subset of teen respondents.

\subsection{Personal experience with guns}

CHIS asked a series of questions about the adolescent respondents’ personal experience with guns. As a preliminary matter it is interesting to observe whether boys are more likely to grow up with guns in the home than girls, as might be the case, for example, if household gun ownership is influenced by the preferences and interests of the child. ${ }^{6}$ In fact, there appears to be little difference (Table II): When a boy is selected as the respondent, $25.3 \%$ of the parents indicate that there is a gun in the home; when a girl is the respondent, $23.7 \%$ of the parents indicate a gun. This difference is not statistically significant. It is also interesting to note that the overall prevalence of guns in marital homes with adolescent children (24.5\%) is almost identical to the prevalence in all marital homes (24.8\%) (Table I). It appears, then, that the presence or absence of adolescent children has little effect on the decision by parents of whether to keep a gun.

A small fraction, 3.3\%, of the teen respondents residing in a marital household own a gun (as indicated by the response to the item "Do you yourself have a gun, either at home or somewhere else?”). Boys outnumber girls as gun owners by a factor of 6 (5.7\% vs. 0.9\%).

\footnotetext{
${ }^{6}$ As will be seen, adolescent boys are much more involved with guns than girls. Unfortunately, the data file does not indicate whether girl respondents have a teenage brother in the household.
} 
The gender gap among teens is also large with respect to experience with guns, as shown in Table II. Boys are more likely than girls to have handled or fired a gun (46\% vs. 19\%), to have gone hunting or shooting with a family member (20\% vs. $8 \%$ ), or to have gone hunting or shooting with anyone (33\% vs. 11\%). ${ }^{7}$ Given this large gap in experience, it would not be surprising if boys tended to know more about their parents’ guns than girls.

\subsection{Teens' reporting of guns in the home}

Teen respondents were asked a question about guns in the home that is similar to the item on the adult questionnaire: “Does any member of your household happen to keep a firearm at home? It could be kept in your home, garage, outdoor storage area, car, truck, or other motor vehicle.” Overall, 23.0\% of teens said “yes,” compared with $24.5 \%$ of their parents. Just 3.3\% of teens said “don’t know.”

As shown in Table III, there is substantial agreement between the responses of the teens and their parents. In $17.5 \%$ of cases both said “yes” to the gun-in-the-home question, and in 69.9\% of cases both said “no” or “don’t know.” The remaining 11.4\% of all cases are divided about evenly between the parent saying "yes" (and the child saying "no) and the reverse. ${ }^{8}$ From another perspective, the teen said "yes" in $71 \%$ of the cases in which the parent said yes, and the parent said "yes" in $76 \%$ of cases in which the teen said "yes."

The gender gap among the teen respondents is evident in the prevalence of "yes” answers shown in Table IV. For all marital households, boys were more likely to say "yes” than girls

\footnotetext{
${ }^{7}$ Readers interested in additional information about adolescents' gun use and handling based on these data are referred to Hemenway and Miller (2004), Miller and Hemenway (2004), and Vittes and Sorenson (in press).

${ }^{8}$ Readers interested in an examination of teen-adult disagreement about guns in the home are referred to Sorenson and Cook (under review).
} 
(25.0\% vs. 21.1\%). Part of that difference may be real -- recall from Table 2 that the parent of a boy respondent was slightly more likely to say yes than the parent of a girl respondent. But that "real" difference is only 1.6 percentage points, compared with the 3.9 percentage point difference in the teen responses. Furthermore (see Table IV), when the sample is restricted to just households in which the parent said "yes,” the gender gap among the teen respondents is 7.4 percentage points ( $74.9 \%$ vs. 67.5$)$. The teen gender gap is much larger when it is the father who responds "yes" (gap equals 11.0 percentage points) than when it is the mother who responds yes (gap equals 2.8 percentage points). One reasonable explanation of this pattern is that girls are much more likely to know about the household gun if the mother knows.

\subsection{Multivariate results}

We carry this analysis one step further by performing a multivariate logistic regression analysis of the teen responses. Table V presents the results for the sample of marital households in which the parent says that there is a gun, and Table VI presents the results of an identical regression for the sample in which the parent says "no" to the gun question. Looking first at Table V, we see that the probability of a "yes" answer (as opposed to "no" or "don’t know”) by the teen is greater if the mother is the adult respondent (especially for the girls), and lower if the teen respondent is a girl. If the household is in a rural area the likelihood of a "yes" increases markedly for girls.

Similar to prior analyses of all adolescents interviewed in CHIS (Sorenson \& Vittes), other things equal, black and Hispanic teens are less likely to report a gun in the home (that has been reported by a parent) than are non-Hispanic whites. Table V reports that this "racial" gap is especially large for boys. 
For households in which the parental respondent says “no," we see (in Table VI) that boys are much more likely to say yes if their mother was the respondent than their father. (Note that in this case the teen's "yes" answer is in contradiction to the parent.) Black boys are much more likely to say “yes” than whites, and Asians are less likely.

In an attempt to understand the gender gap in these results, we turn again to the notion of "public-ness" of the household guns, and in particular whether the family uses their guns for sporting purposes.

\subsection{Hunting and shooting}

As noted previously (see Table II), about 14\% of the teen respondents say they have gone hunting or shooting with a member of the family. Unsurprisingly, the household guns in these households are "public" in the sense of being known to the teen respondents. Whether the adolescent reports that he or she has been "hunting or shooting" appears to account for the teen gender gap. For households where the parent respondent says "yes," nearly 90\% of both boys and girls say "yes" if they also say that they have been hunting or shooting with a family member. The fraction of adolescents who report that they have a gun in the home drops substantially if they have not been hunting or shooting. But in either case the gap disappears when conditioned on this item, and even is reversed slightly for the older teens (Table VII). So one simple account of the teen gender gap is that it is the result of personal experience with gun sports, which is much more common among boys than girls.

In our multivariate analysis, conditioning on "hunting or shooting" is of considerable importance in predicting a "yes" answer by the teen respondent. When the adult respondent reported that there was a gun in the home, the regression coefficient for "hunting or shooting" 
was 1.065 for boys and 2.050 for girls. When the adult respondent reported that there was not a gun in the home, the regression coefficient for "hunting or shooting” was 1.283 for boys and 1.184 for girls. Each coefficient was statistically significant at $\mathrm{p}<.01$. Of central importance to the present investigation, including whether the teen had been hunting or shooting eliminates the effect of the teen's gender.

The "rural” variable remains statistically important, however, suggesting that rural residence is not just a proxy for participation in gun sports. The differences by race and ethnicity remain, but in slightly muted form. The tabled data, not presented here due to space limitations, are available upon request from the authors.

\section{Summary and Discussion}

Our results can be briefly summarized. They have implications for both survey design and for providing some insight into the role of guns in the life of a family.

For marital households in which one spouse is selected at random and interviewed in a survey, husbands are substantially more likely to report a gun in the home than wives. As we have demonstrated, that peculiar but reliable feature of national surveys is also a feature of the California Health Interview Survey of 2001. In the CHIS, husbands are 1.36 times as likely to report a gun. When asked about handguns in particular, husbands report many more than wives; a survey of husbands only would estimate over twice as many handguns in marital homes as a survey of wives only.

A unique feature of the CHIS is that in some surveyed households, adolescent children were interviewed after the interview with a parent. Based on the results of these teen interviews we find that the proportional gender gap in reporting is as large for the teens as for their parents. 
The teen gap is in a sense the result of a difference in involvement with guns: accounting for participation in family gun sports, there is essentially no difference in reporting of guns by boys and girls.

The present work extends the work of Sheley and Wright (1993) which found that participation in shooting sports was associated with higher rates of gun ownership among adolescents. CHIS data indicate that recreational gun use is positively associated with adolescents' reports of having a gun in the home and that recreational gun use accounts for the gender gap in adolescents' reports about household guns.

It is intriguing that in over a quarter of the cases in which the teen says there is a gun in the home, the adult respondent says there is not. We might interpret this difference as ignorance or perhaps bravado on the part of the teens. Alternatively, it is possible that the teen is telling the truth in most of these cases, and that the teen is better informed or more willing to trust the interviewer than is the parent respondent. One implication of this latter assumption is that the true prevalence of gun ownership in marital households may be substantially higher than suggested by the adult responses. Here are several alternative prevalence estimates, in each case with the source noted:

- Martial households with teens - Fraction of “yes” of adult (parent) responses: $24.5 \%$

- Marital households with teens, father is adult respondent - Fraction “yes” of male adult (father) responses: $28.2 \%$

- Marital households with teens, father is adult respondent - Fraction "yes” by either father responses or teen responses or both: $32.5 \%$ 
Thus, if all response errors for the gun item are to conceal an existing gun, we estimate that about one-third, rather than one quarter, of these households have guns. ${ }^{9}$

Gender disparities also are relevant to the design of case-control studies of the risks of keeping a gun in the home, where it is necessary to ascertain gun possession in both "cases" and “controls” (Kellermann et al., 1993; Wiebe 2003). In a recent study, for example, Wiebe (2003) analyzed the likelihood of homicide and suicide victimization as a function of whether there was a gun in the home. Gun possession was determined by interviewing next of kin for the victims (“cases”), but for the age- and gender-matched "controls" it was determined by interviewing the individuals themselves. That suggests that many of the male victims would have female respondents on the gun-possession item, while the controls have male respondents. Thus, the finding that guns are more common in the homes of homicide victims is strengthened, perhaps, inadvertently, by the study design.

The fact that the teen gap in reports of whether there is a gun in the home disappears once personal experience with guns is taken into account suggests that knowledge may account for much of the gap. Future surveys assessing whether there is a gun in the home may benefit from the inclusion of questions about experience with guns. Doing so would allow for further examination of the possible basis for the gender discrepancy in reports of household firearms.

\footnotetext{
${ }^{9}$ It would have been useful to examine parent-teen agreement about other household goods, but CHIS did not include questions that would allow for such a comparison. Although there is a long-established literature on parent-child agreement in psychology on topics such as mood and behavior, to our knowledge, the published peer-reviewed literature does not include such comparisons for household goods.
} 


\section{References}

California Health Interview Survey (2002). CHIS 2001 Methodology Reports. Los Angeles, CA: UCLA Center for Health Policy Research. Available at: www.chis.ucla.edu

Cook, P.J. and Ludwig, J. (1996). Guns in America: Results of a Comprehensive Survey of Gun Ownership and Use Washington, DC: The Policy Foundation.

Hemenway, D., and Miller, M. (2004). Gun threats and self-defense gun use by California adolescents. Archives of Pediatric and Adolescent Medicine, 158:395-400.

Kellermann, A.L., Rivara, F.P., Rushforth N.B., et al. (1993). Gun ownership as a risk factor for homicide in the home. N Engl J Med. 329: 1084-1091.

Kleck, G. (1997). Targeting Guns: Firearms and their Control. Hawthorne, New York: Aldine de Gruyter.

Lizotte, A. J., Tesoriero, J., Thornberry, T., and Krohn, M. D. (1994). Patterns of adolescent firearms ownership and use. Justice Quarterly, 11:51-74.

Ludwig, J, Cook, P.J., and Smith, T.W. (1998). “The gender gap in reporting household gun ownership” American Journal of Public Health 88 (11), Nov.: 1715-1718.

Miller, M., and Hemenway, D. (2004). Unsupervised use of firearms by California adolescents. Injury Prevention, 10:163-168.

Sheley, J.F., and Wright, J.D. (1993). Gun Acquisition and Possession in Selected Juvenile Samples. Research in Brief. Washington, D.C. U.S. Department of Justice, Office of Justice Programs, National Institute of Justice.

Sorenson, S. B, and Vittes, K. A. (2003). Adolescents and firearms: A statewide California survey. American Journal of Public Health, 94:852-858.

Teret, S. P., Webster, D.W. Vernick, J.S., Smith, T.W., Leff, D., Wintemute, G.J., Cook, P.J., Hawkins, D.F., Kellermann, A.L., Sorenson, S.B., DeFrancesco, S. (1998). "Support for new policies to regulate firearms - Results of two national surveys.” N Engl J of Med 339, September 17: 813-818

Vittes, K. A. and Sorenson, S. B. (in press). Recreational gun use by California adolescents. Health Education and Behavior.

Wiebe, DF (2003). Homicide and suicide risks associated with firearms in the home: A national case-control study. Ann Emerg Med 41(6): 771-782.

Zimring, F.E. (2003). “Continuity and change in the American gun debate.” In Evaluating Gun Policy, ed. Ludwig J., and Cook, P.J. Washington, DC: Brookings Institution Press: 441-453. 


\section{Acknowledgment}

The Adolescent Gun Survey, a supplement to the California Health Interview Survey, and the preparation of this manuscript were funded by the Joyce Foundation and the David and Lucile Packard Foundation. 
Table I

Adult reports of guns in the home, marital households in California, by adult gender

$\begin{array}{lll}\stackrel{2}{\text { Adult Gender }} \text { Husband } & \text { Wife } & \text { Overall } \\ \mathrm{n}=12,642 & \mathrm{n}=15,168 & \mathrm{n}=27,810\end{array}$

Gun in the home

$\begin{array}{llll}\text { Yes } & 28.5 \% & 21.0 \% & 24.8 \% \\ \text { No } & 67.3 \% & 76.3 \% & 71.7 \% \\ \text { Don't know } & 4.2 \% & 2.7 \% & 3.5 \%\end{array}$

xxHandgun in the home??

Perhaps we want estimates of having a handgun in the home before we move into the number of handguns?

Number of handguns in the home

$\begin{array}{llll}\text { None } & 80.5 \% & 87.1 \% & 83.7 \% \\ \text { One } & 9.4 \% & 7.2 \% & 8.3 \% \\ \text { Two } & 4.4 \% & 2.7 \% & 3.6 \% \\ \text { Three or more } & 4.4 \% & 1.6 \% & 3.0 \% \\ \text { Don't know } & 1.4 \% & 1.4 \% & 1.4 \% \\ \text { Mean number }^{1} & 0.44 & 0.20 & 0.32\end{array}$

Note. Unweighted n's are shown; weights were applied to the data.

1 “Don't know” responses were excluded from this calculation. 


\section{Table II}

Teens' experiences with guns, marital households containing an adolescent, California, by adolescent respondent gender, \%

\begin{tabular}{lll}
\multicolumn{2}{l}{ Adolescent gender } \\
Boy & Girl & Overall \\
$n=2,054$ & $n=2,045$ & $n=4,099$
\end{tabular}

Gun in the home

(per adult respondent)

Teen owns gun

25.3

5.7

23.7

24.5

Teen has handled or fired a gun

45.6

0.9

3.3

Teen has gone hunting or shooting with a family member

20.1

19.4

32.5

Teen has gone hunting or shooting with anyone

33.1

7.6

13.8

Note. Unweighted n's are shown; weights were applied to the data. 
Table III

Reports of a gun in the home, adult by teen responses, martial households containing an adolescent, California, \%

\begin{tabular}{lllll}
\hline & \multicolumn{4}{c}{ Adolescent_(n=4,099) } \\
\cline { 2 - 5 } & Yes & No & Don’t know & Overall \\
\hline Parent $(\mathrm{n}=4,099)$ & & & & \\
Yes & 17.5 & 5.8 & 1.2 & 24.5 \\
No or don't know & 5.6 & 67.8 & 2.1 & 75.5 \\
Overall & 23.0 & 73.6 & 3.3 & 100.0 \\
\hline
\end{tabular}

Note. Unweighted n's are shown; weights were applied to the data. 
Table IV

Teen reports of a gun in the home, by gender, martial households containing an adolescent, California, \%

\begin{tabular}{ll}
\multicolumn{2}{l}{ Adolescent gender } \\
$\begin{array}{ll}\text { Boy } & \text { Girl } \\
n=2,054 & n=2,045\end{array}$
\end{tabular}

Overall $(n=4,099)$

25.0

21.1

When parent says yes $(n=1,249)$

Male adult $(\mathrm{n}=622)$

74.9

67.5

$72.5 \quad 61.5$

Female adult $(\mathrm{n}=627)$

78.2

75.4

Note. Unweighted n's are shown; weights were applied to the data. 
Table V

Regression coefficients for determinants of teen response on household gun question, by gender, marital households in California in which the adult reports that there is a gun

\begin{tabular}{|c|c|c|c|}
\hline & $\begin{array}{l}\text { Overall } \\
n=1,249\end{array}$ & $\begin{array}{l}\text { Boy } \\
n=629\end{array}$ & $\begin{array}{l}\text { Girl } \\
\mathrm{n}=620\end{array}$ \\
\hline $\begin{array}{l}\text { Female adult } \\
\text { (vs. male) }\end{array}$ & $\begin{array}{l}0.501 * * \\
(0.134)\end{array}$ & $\begin{array}{l}0.237 \\
(0.199)\end{array}$ & $\begin{array}{l}0.762 * * \\
(0.187)\end{array}$ \\
\hline $\begin{array}{l}\mathrm{HH} \text { is in rural area } \\
\text { (vs. xx area) }\end{array}$ & $\begin{array}{l}0.373^{*} \\
(0.163)\end{array}$ & $\begin{array}{l}0.088 \\
(0.229)\end{array}$ & $\begin{array}{l}0.688 * * \\
(0.236)\end{array}$ \\
\hline Child is 13 (vs.12) & $\begin{array}{l}0.404 \\
(0.203)\end{array}$ & $\begin{array}{l}0.281 \\
(0.302)\end{array}$ & $\begin{array}{l}0.477 \\
(0.307)\end{array}$ \\
\hline Child is 14 & $\begin{array}{l}0.605 * * \\
(0.230)\end{array}$ & $\begin{array}{l}0.787^{*} \\
(0.329)\end{array}$ & $\begin{array}{l}0.511 \\
(0.333)\end{array}$ \\
\hline Child is 15 & $\begin{array}{l}0.736 * * \\
(0.232)\end{array}$ & $\begin{array}{l}0.680 * \\
(0.337)\end{array}$ & $\begin{array}{l}0.899 * * \\
(0.332)\end{array}$ \\
\hline Child is 16 & $\begin{array}{l}0.375 * \\
(0.221)\end{array}$ & $\begin{array}{l}0.199 \\
(0.310)\end{array}$ & $\begin{array}{l}0.564 \\
(0.322)\end{array}$ \\
\hline Child is 17 & $\begin{array}{l}0.911 * * \\
(0.226)\end{array}$ & $\begin{array}{l}1.042 * \\
(0.349)\end{array}$ & $\begin{array}{l}0.791^{*} \\
(0.308)\end{array}$ \\
\hline $\begin{array}{l}\text { Girl respondent } \\
\text { (vs. boy) }\end{array}$ & $\begin{array}{l}-0.348^{* *} \\
(0.134)\end{array}$ & -- & -- \\
\hline $\begin{array}{l}\text { Child and adult respondent } \\
\text { are of the same sex }\end{array}$ & $\begin{array}{l}0.218 \\
(0.134)\end{array}$ & -- & -- \\
\hline Black (vs. White) & $\begin{array}{l}-0.774^{*} \\
(0.337)\end{array}$ & $\begin{array}{l}-1.168 * * \\
(0.432)\end{array}$ & $\begin{array}{l}-0.509 \\
(0.547)\end{array}$ \\
\hline Hispanic $^{1}$ & $\begin{array}{l}-0.546^{* *} \\
(0.157)\end{array}$ & $\begin{array}{l}-0.725^{* *} \\
(0.234)\end{array}$ & $\begin{array}{l}-0.383 \\
(0.213)\end{array}$ \\
\hline Asian & $\begin{array}{l}-0.434 \\
(0.274)\end{array}$ & $\begin{array}{l}-1.401^{* *} \\
(0.381)\end{array}$ & $\begin{array}{l}0.622 \\
(0.435)\end{array}$ \\
\hline Other & $\begin{array}{l}-0.312 \\
(0.409)\end{array}$ & $\begin{array}{l}0.130 \\
(0.668)\end{array}$ & $\begin{array}{l}-0.638 \\
(0.546)\end{array}$ \\
\hline Intercept & $\begin{array}{l}0.372 \\
(0.206)\end{array}$ & $\begin{array}{l}0.810 * * \\
(0.255)\end{array}$ & $\begin{array}{l}-0.184 \\
(0.264)\end{array}$ \\
\hline
\end{tabular}

Note. Unweighted n's are shown; weights were applied to the data. The multivariate logistic regression took into account all other variables reported in the table. Standard errors are reported in parentheses.

${ }^{1}$ Hispanic is exclusive of other ethnic groups.

$* \mathrm{p}<.05 * * \mathrm{p}<.01$ 
Table VI

Regression coefficients for determinants of teen responses on household gun question, by gender, marital households in California in which the adult reports that there is not a gun

\begin{tabular}{|c|c|c|c|}
\hline & $\begin{array}{l}\text { Overall } \\
n=2,850\end{array}$ & $\begin{array}{l}\text { Boy } \\
n=1,425\end{array}$ & $\begin{array}{l}\text { Girl } \\
n=1,425\end{array}$ \\
\hline $\begin{array}{l}\text { Female adult } \\
\text { (vs. male) }\end{array}$ & $\begin{array}{l}0.373 * \\
(0.151)\end{array}$ & $\begin{array}{l}0.840 * * \\
(0.212)\end{array}$ & $\begin{array}{l}0.076 \\
(.219)\end{array}$ \\
\hline $\begin{array}{l}\mathrm{HH} \text { is in rural area } \\
\text { (vs. xx area) }\end{array}$ & $\begin{array}{l}0.909 * * \\
(0.177)\end{array}$ & $\begin{array}{l}0.719 * * \\
(0.263)\end{array}$ & $\begin{array}{l}1.170 * * \\
(0.245)\end{array}$ \\
\hline Child is 13 (vs. 12) & $\begin{array}{l}0.434 \\
(0.281)\end{array}$ & $\begin{array}{l}-0.158 \\
(0.348)\end{array}$ & $\begin{array}{l}1.567 * * \\
(0.564)\end{array}$ \\
\hline Child is 14 & $\begin{array}{l}0.584 * \\
(0.282)\end{array}$ & $\begin{array}{l}-0.078 \\
(0.348)\end{array}$ & $\begin{array}{l}1.552 * * \\
(0.567)\end{array}$ \\
\hline Child is 15 & $\begin{array}{l}0.560^{*} \\
(0.282)\end{array}$ & $\begin{array}{l}0.263 \\
(0.343)\end{array}$ & $\begin{array}{l}1.273^{*} \\
(0.570)\end{array}$ \\
\hline Child is 16 & $\begin{array}{l}0.902 * * \\
(0.271)\end{array}$ & $\begin{array}{l}0.592 \\
(0.320)\end{array}$ & $\begin{array}{l}1.655 * * \\
(0.568)\end{array}$ \\
\hline Child is 17 & $\begin{array}{l}0.684^{*} \\
(0.285)\end{array}$ & $\begin{array}{l}-0.174 \\
(0.393)\end{array}$ & $\begin{array}{l}1.920 * * \\
(0.556)\end{array}$ \\
\hline $\begin{array}{l}\text { Girl respondent } \\
\text { (vs. boy) }\end{array}$ & $\begin{array}{l}-0.130 \\
(0.151)\end{array}$ & -- & -- \\
\hline $\begin{array}{l}\text { Child and adult respondent } \\
\text { are of the same sex }\end{array}$ & $\begin{array}{l}-0.450 * * \\
(0.151)\end{array}$ & -- & -- \\
\hline Black (vs. White) & $\begin{array}{l}0.542 \\
(0.295)\end{array}$ & $\begin{array}{l}0.968 * * \\
(0.361)\end{array}$ & $\begin{array}{l}-0.082 \\
(0.568)\end{array}$ \\
\hline Hispanic $^{1}$ & $\begin{array}{l}-0.287 \\
(0.161)\end{array}$ & $\begin{array}{l}-0.007 \\
(0.219)\end{array}$ & $\begin{array}{l}-0.604^{*} \\
(0.244)\end{array}$ \\
\hline Asian & $\begin{array}{l}-0.756 * * \\
(0.291)\end{array}$ & $\begin{array}{l}-0.407 \\
(0.385)\end{array}$ & $\begin{array}{l}-1.128 * \\
(0.452)\end{array}$ \\
\hline Other & $\begin{array}{l}0.544 \\
(0.517)\end{array}$ & $\begin{array}{c}0.685 \\
(0.856)\end{array}$ & $\begin{array}{l}-0.394 \\
(0.657)\end{array}$ \\
\hline Intercept & $\begin{array}{l}-3.027 * * \\
(0.267)\end{array}$ & $\begin{array}{l}-3.203 * * \\
(0.313)\end{array}$ & $\begin{array}{l}-3.953 * * \\
(0.531)\end{array}$ \\
\hline
\end{tabular}

Note. Unweighted n's are shown; weights were applied to the data. The multivariate logistic regression took into account all other variables listed in the table. Standard errors are reported in parentheses.

${ }^{1}$ Hispanic is exclusive of other ethnic groups.

$* \mathrm{p}<.05 * * \mathrm{p}<.01$ 


\section{Table VII}

Teen reports of guns in the home, in California married households in which the adult reports there is a gun, \%

\begin{tabular}{lll}
\hline & \multicolumn{2}{l}{ Teen gender } \\
& Boy & Girl \\
\hline 12- to 17-year olds (n=4,099) & 74.9 & 67.5 \\
Overall & & \\
If adolescent hunts or shoots & 89.1 & 87.1 \\
$\quad$ Yes (n=446) & 64.2 & 63.4 \\
$\quad$ & & \\
$\quad$ No (n=803) & 77.9 & 70.8 \\
15- to 17-year olds (n=xxx) & & \\
Overall & 88.4 & 89.8 \\
If adolescent hunts or shoots & 65.4 & 66.1 \\
$\quad$ Yes (n=265) & & \\
$\quad$ No (n=371) &
\end{tabular}

Note. Unweighted n's are shown; weights were applied to the data. 